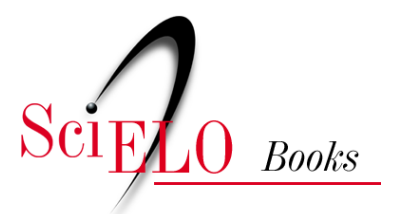

\title{
Balsas e balseiros
}

\author{
José Carlos Radin \\ Gentil Corazza
}

\section{SciELO Books / SciELO Livros / SciELO Libros}

RADIN, J.C., and CORAZZA, G. Balsas e balseiros. In: Dicionário histórico-social do Oeste catarinense [online]. Chapecó: Editora UFFS, 2018, pp. 22-26. ISBN: 978-85-64905-65-8. https://doi.org/10.7476/9788564905658.0005.

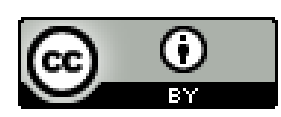

All the contents of this work, except where otherwise noted, is licensed under a Creative Commons Attribution 4.0 International license.

Todo o conteúdo deste trabalho, exceto quando houver ressalva, é publicado sob a licença Creative Commons Atribição 4.0.

Todo el contenido de esta obra, excepto donde se indique lo contrario, está bajo licencia de la licencia $\underline{\text { Creative Commons }}$ Reconocimento 4.0. 


\section{Balsas e balseiros}

As balsas eram composições de madeira, aglomerados de troncos, toras ou tábuas serradas, armadas para transportar as madeiras oriundas do Oeste catarinense, através do rio Uruguai, até o principal porto de destino, que era São Borja, no Rio Grande do Sul, de onde eram rebocadas ao Rio da Prata, para depois serem exportadas. Para a armação das balsas as madeiras eram arrastadas ou levadas em carroças ou caminhões, até a barranca do rio Uruguai e de seus afluentes, de acordo com a previsão de cheias do rio Uruguai. Os balseiros eram os trabalhadores, caboclos e agricultores que montavam as balsas e as conduziam até os portos de destino, com o objetivo de ganhar uma renda extra, num trabalho sazonal, nos períodos das cheias.

As atividades das balsas e dos balseiros abrangeram um período de aproximadamente 30 anos, basicamente entre 1930-1960. Iniciado na década de 1930, o ciclo da madeira já representava mais de vinte por cento do valor total das exportações do Estado de Santa Catarina, na década de 1940, chegando a cinquenta por cento de todo o volume exportado no período entre 1950 e 1960 . Tais atividades se inseriam no contexto socioeconômico da região no período mais intenso de extração da madeira, em que as estradas e os meios de transporte eram muito precários. Nessas circunstâncias, por oferecerem condições de navegabilidade nos períodos de cheias, o rio Uruguai e seus afluentes, que permeiam parte do território do Oeste catarinense, mostravam-se como uma solução para o escoamento das madeiras da região.

Os principais locais de partida das balsas eram Entre Rios, Porto Itá, Barra do Uvá, Linha Simon, Porto de Goio-en, Chalana, Caxambu, São Carlos, Mondaí e Itapiranga. O percurso entre o local de origem e o destino era de aproximadamente 500 quilômetros e demorava, em média, de três a cinco dias para ser percorrido. As madeiras, na forma de tábuas ou de toras, eram oriundas de pinos ou madeira de lei, como cedro, louro, pinheiro, canela e outros de boa qualidade, abundantes nas matas da região. Cada balsa possuía entre 180 e 200 toras, que podiam ter até 10 metros de comprimento. Cada 10 ou 15 toras 
formava um "Pelotão". As tábuas mediam 5,5 metros. Todas as madeiras eram agrupadas, de acordo com o seu comprimento, e amarradas com cipós ou mesmo com arame galvanizado a travessas de madeira de 20 ou 25 centímetros de diâmetro. Uma balsa de toras podia atingir entre 130 a 150 metros de comprimento. Acima disso, teriam dificuldade de deslocamento em face das muitas curvas do rio Uruguai.

Os balseiros enfrentavam condições de trabalho muito precárias, sem qualquer equipamento de segurança, nem assistência médica e social. Os frequentes acidentes eram um risco que os balseiros tinham que enfrentar por sua própria conta, porque não havia seguro ou qualquer mecanismo de indenização. Tratava-se de uma mão de obra barata e sem garantias de direitos sociais e trabalhistas. Os balseiros levavam uma vida nômade e desprotegida de qualquer assistência e registro na Capitania dos Portos ou no Instituto dos Marítimos. O número de balseiros empregados em cada balsa variava entre dez ou quinze homens, de acordo com o tamanho da balsa, a época da viagem, a capacidade da empresa e a disponibilidade de pessoal. Não há notícias de mulheres que trabalhassem como balseiras. As balsas eram conduzidas por um balseiro prático, que tinha muita experiência no seu ofício. Ele devia conhecer tudo, desde a formação da balsa, o momento certo para o início da viagem, o nível do rio, as corredeiras e os lugares mais perigosos.

As viagens eram feitas em época das cheias, que normalmente aconteciam durante o inverno, mas, eventualmente, podiam ocorrer também durante o verão. Em geral, não costumava haver mais do que quatro enchentes por ano. Nos anos de 1944 e 1945, por exemplo, não ocorreram enchentes, mas em 1946 choveu muito. As enchentes eram ansiosamente aguardadas e tidas como uma "dádiva de Deus", como canta a música de Cenair Maicá "Balseiros do Rio Uruguai": "Oba, viva, veio a enchente, o Uruguai transbordou, vai dar serviço prá gente. Vou soltar minha balsa no rio, vou rever maravilhas, que ninguém descobriu". Mas aquelas expectativas não se realizavam quando não chegava a enchente, provocando grandes frustrações, pelos prejuízos que representavam para a renda dos trabalhadores e para a economia da região. 
Para que uma viagem fosse iniciada, o nível das águas devia estar pelo menos 6 metros acima do normal, no entanto, muitas vezes, as viagens eram feitas com níveis menores. Quanto maior o nível da água, mais rápida era a correnteza e, portanto, menor o tempo da viagem; por outro lado, a velocidade aumentava os riscos e os perigos do percurso. Muitas vezes, as cheias chegavam inesperadamente, fazendo com que se apressasse a montagem das balsas para não se perder a oportunidade, pois a exploração da madeira era a principal atividade econômica da região no período que ia dos anos 1930 a final de 1950. A pressa na montagem das balsas poderia também comprometer a segurança, pois o êxito da viagem dependia muito do estado de amarração das balsas. A viagem podia durar até cinco ou seis dias, navegando-se dia e noite.

Inicialmente as balsas eram manobradas com remos e, mais tarde, também puxadas por barcos a motor. Os balseiros, que conduziam as embarcações, se abrigavam em pequenos ranchos feitos sobre as balsas com madeiras, folhas de árvores ou capim. Havia também um rancho para a cozinha. Quando o rio estava manso e o trajeto ocorria de forma tranquila, muitos patrões acompanhavam as balsas, porém, em geral, seguiam por terra, por considerarem ser mais seguro. A viagem era sempre uma aventura, cheia de perigos. Ao longo do percurso, havia ilhas, remansos, ressorjos e corredeiras, muitos deles bastante perigosos, como o Salto Grande, a Ilha Comprida, as Nove Voltas, as Ilhas Gêmeas. Salto Grande talvez fosse o mais perigoso para as embarcações. Do Porto de Itá até São Borja, contavam-se 49 pontos de referência da viagem, entre portos, saltos, ilhas, enseadas, corredeiras, remansos e os ressorjos ou redemoinhos. Como esses locais exigiam toda a atenção possível, os balseiros passavam dia e noite sem dormir quando atravessavam esses pontos. Muitas toras desprendiam-se das amarrações e se perdiam no rio. Da mesma forma, muitas balsas se desmanchavam e não chegavam ao destino. Eram 16 quilômetros acidentados de muita velocidade das águas. Os acidentes eram frequentes. Como sabiam dos perigos e dos acidentes, os moradores das margens do rio Uruguai estavam sempre preparados para atender possíveis pedidos de socorro de balseiros acidentados. Durante a viagem, havia 
uma divisão do trabalho entre o prático, os remadores e o cozinheiro, mas nas horas mais difíceis todos ajudavam nos remos. Os donos das balsas, em geral pessoas economicamente mais abastadas da região, empresários madeireiros, costumavam fornecer a alimentação para as viagens. A água para beber era levada em garrafões e, quando faltava, reabastecia-se em alguma fonte ou se usavam tubos de bambu para chupar a água do fundo do rio, que era mais limpa.

Quando os balseiros chegavam ao seu destino, em São Borja, encontravam com o patrão, que já estava à espera dos empregados e das madeiras. Algumas vezes eram recepcionados com um churrasco, para comemorar a chegada. Ali mesmo, os trabalhadores recebiam o pagamento. Alguns balseiros gastavam o seu dinheiro em São Borja, em diversões e mercadorias em geral que eram difíceis de obter nos seus locais de residência. Entretanto, a maioria dos trabalhadores do rio trazia o ganho para casa, a fim de investir nos negócios familiares. Em cinco dias, recebiam o valor de dois meses de trabalho normal na região. O retorno acontecia por via terrestre. De São Borja até Santa Maria os balseiros iam de trem. De Santa Maria a Erechim, de ônibus e, depois, andavam a pé até Itá, num percurso de aproximadamente cinquenta quilômetros. A partir dos anos 1950, passou-se a utilizar o caminhão para o transporte dos balseiros, de São Borja até Erechim, e depois os trabalhadores viajavam em ônibus até Itá.

Com a abertura de novas estradas e a implantação de outros meios de transporte, abriram-se perspectivas para o mercado interno da madeira, decaindo a exportação via rio Uruguai.

Essa atividade foi vista como 'Odisseia de balseiros', uma espécie de 'mercantilismo fluvial' que contribuiu para centralizar recursos financeiros nas mãos de madeireiros e comerciantes. O extrativismo foi uma das primeiras atividades capitalistas mais significativas na região, provocando uma renovação na sua vida econômica. O escoamento da madeira, por meio de balsas no rio Uruguai, figurou entre as principais atividades econômicas a partir dos anos 1920, mantendo-se bastante ativa até meados do século. 


\section{REFERÊNCIAS}

BELLANI, Eli Maria. Balsas e balseiros no Rio Uruguai (1930-1950).

CEOM: 20 anos de memórias e histórias no Oeste de Santa Catarina.

Chapecó: Cadernos do CEOM - Ano 19, n. 23, 2006.

. Madeiras, balsas e balseiros no Rio Uruguai. Florianópolis:

EdiUFSC, 1991.

BRUM DE OLIVEIRA, Noeli Woloszyn. Os Trabalhadores do Rio: balsas

e balseiros do Alto Uruguai: 1930-1960. (Dissertação de Mestrado) Passo

Fundo: UPF, 2006.

CORREIO RIOGRANDENSE. Odisseia dos Balseiros. Caxias do Sul, 8/11/1995, ano 87, n. 4.451.

MAICÁ, Cenair. Balseiros do rio Uruguai. (Música). Disponível em:

<https://www.letras.mus.br/cenair-maica/174315/>. Acesso em: 15 mar.

2017. 